\title{
SOME NOTES ON THE TEXT
}

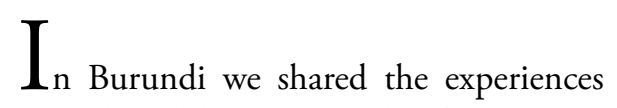

described in this book, and we likewise shared the responsibility for recounting them. Kathleen wrote Chapters 6, 7, II, I2, I3, I4, and I5; Bob took care of the rest.

Parts of the story are told through dialogue. The words attributed to speakers come either from tape recordings, Kathleen's video camera, written notes and speeches, or recollections from participants in the conversations. While recollections will include slight inaccuracies, they nevertheless conform more closely to what was said than would attempts to paraphrase. While most names in the text are accurate as given, in a very few instances pseudonyms are used to protect the identities of certain persons still in $\mathrm{Bu}$ rundi, whose lives might be endangered if their identities were revealed. 
THIS PAGE INTENTIONALLY LEFT BLANK 
THIS PAGE INTENTIONALLY LEFT BLANK 